\title{
Matéria
}

Revista Matéria, v. 14, n. 4, pp. 1179 - 1187, 2009

ISSN 1517-7076

http://www.materia.coppe.ufrj.br/sarra/artigos/artigo11116

\section{Desenvolvimento de metodologia e estudo do potencial da técnica TOFD visando a inspeção e o monitoramento de equipamentos}

\author{
SOUZA, R.R.; MARTINS, C.O.D.; LIMA, T.R.S.; REGULY, A.
}

Laboratório de Metalurgia Física, Universidade Federal do Rio Grande do Sul. Av. Osvaldo Aranha, 99, S610, CEP: 90035-190, Porto Alegre - RS - Brasil.

ricson@demet.ufrgs.br, cmartins@demet.ufrgs.br, tlima@demet.ufrgs.br, reguly@demet.ufrgs.br

\begin{abstract}
RESUMO
Com o constante crescimento da indústria nacional, cresce também a demanda pelo desenvolvimento de ferramentas eficientes de inspeção e monitoramento da integridade estrutural de equipamentos e estruturas. Dentre estas, destacam-se os ensaios não destrutivos. Das diversas técnicas não destrutivas aplicadas para a inspeção de componentes, destaca-se o uso da técnica de ultra-som convencional para a localização e dimensionamento de defeitos. Porém, em inspeções de campo, devido ao desconhecimento freqüente da orientação dos defeitos, recorre-se a metodologias que utilizam diversos ângulos incidentes e sistemas de análise de sinais, resultando num processo lento e subjetivo de inspeção. Com o aumento da demanda por medidas on line, tem-se elevado a necessidade de processos mais rápidos e confiáveis, dentre estes, destaca-se o uso da técnica de ultra-som via time of flight diffraction (TOFD). Este trabalho apresenta a técnica TOFD como uma ferramenta eficiente na determinação da profundidade de entalhes usinados em blocos de aço SAE 1022, a partir da calibração segundo Norma Britânica BS 7706:1993. Para isso, foi elaborada uma metodologia utilizando quatro variações (freqüência/ângulo) diferentes de inspeção, verificando o potencial do método na análise das diferentes profundidades, a fim de aplicar na inspeção e no monitoramento de equipamentos. Os resultados mostram que tanto para defeitos aflorando na superfície de varredura quanto para defeitos aflorando na superfície oposta, o dimensionamento pode ser preciso, se a variação adequada (freqüência/ângulo) para cada caso for selecionada.
\end{abstract}

Palavras-chaves: ensaios não destrutivos, confiabilidade operacional, TOFD.

\section{Development of methodologies applied to inspection of components by TOFD technique}

\section{ABSTRACT}

With the constant growth of the domestic industry, the demand for the development of efficient tools for inspection and monitoring of structural integrity of equipment and structures also grows. Among these, non-destructive testing have been used. Considering to the non-destructive techniques applied to inspection of components used in oil industries, the use of the conventional ultra-sound technique for location and sizing of defects has proved to be important. However, in the field inspections, due to the frequent lack of orientation of defects, are utilized methodologies that use many incident angles and systems analysis of signals, resulting in a slow and subjective inspection. With the increasing of demand for online inspection, the necessity for faster and more reliable processes has been raised, among these, the use of the time of flight diffraction. This work presents TOFD technique as an efficient tool to determine the height of artificials reflectors machined in samples of SAE 1022 steel, from calibration according to British Standard 7706:1993. For this, it was elaborated a methodology using four different variations (frequency / angle) of inspection, verifying the potential of the method in analysis of different heights, in order to apply in inspection and monitoring of equipments. Results show that as for notches breaking in the surface inspected as for notches breaking in the inside surface, opposite the scanned surface, sizing can be precise, if the correct variation (frequency / angle) for each case was chosen.

Keywords: non destructive test, operational confiabillity, TOFD. 


\section{INTRODUÇÃO}

A falha catastrófica de componentes e estruturas vêm sempre acompanhadas de prejuízos financeiros, geralmente, inadmissíveis, os quais elevam os custos de produção e justificam as pesquisas em manutenção da integridade estrutural, mostrou MARTINS [1]. Neste sentido, esforços estão sendo destinados para o desenvolvimento de diversas ferramentas, principalmente, utilizando as técnicas de ensaios não destrutivos.

Dentre as diversas técnicas disponíveis, destacam-se o uso do controle manual por ultra-som convencional e o método radiográfico para a localização e dimensionamento de descontinuidades. Em inspeções de campo, devido ao freqüente desconhecimento da geometria e da localização das descontinuidades, necessita-se a utilização de diferentes ângulos de incidência e a análise da amplitude dos ecos, resultando num processo lento, subjetivo e dispendioso, revelaram BARROS e CALDEIRA [2]. Além disso, VEIGA et al. [3] disseram que o dimensionamento preciso de defeitos perpendiculares à superfície de inspeção é uma das limitações das técnicas convencionais de ultra-som. Outras dificuldades, segundo SILVA et al. [4], encontradas na inspeção de materiais metálicos, como a detecção de trincas paralelas ao feixe de raios-x, representam um problema há muitos anos. Neste sentido, torna-se necessário o desenvolvimento de sistemas eficientes de inspeção e monitoramento de componentes e estruturas, capazes de automação e de rápida aplicação, como a técnica de ultra-som via TOFD - "Time of Flight Diffraction” ou Tempo de Vôo da Onda Difratada, ou usualmente: TOFD. Antes do uso do TOFD, a deteç̧ão e o dimensionamento das descontinuidades com técnicas ultra-sônicas usualmente utilizavam a amplitude do eco obtida e relacionavam cada amplitude diretamente a dimensão da descontinuidade, mostraram MOURA et al. [5] . Para a utilização do TOFD, SILVA et al. [] ] indicaram que a determinação dos fatores envolvidos na inspeção, tais como: tamanho, forma e orientação do defeito; ângulo e freqüência dos transdutores; espessura do material e parâmetros de varredura são imprescindíveis. Além disso, de acordo com KENZIE e SPECK [7], o TOFD fornece uma melhor correlação entre as alturas das trincas medidas e reais do que a técnica da queda do eco em 20dB, por exemplo.

O TOFD utiliza um par de cabeçotes (um transmissor e um receptor) colocados sobre a mesma superfície do objeto de teste. A separação dos cabeçotes, também chamada de PCS ("Probe Center Separation" - Centro de separação dos sensores), é ajustada de acordo com a espessura de parede da amostra. O scanner com os cabeçotes é movido paralelamente à região provável dos defeitos. Uma onda longitudinal é enviada pelo transmissor em direção ao receptor. O primeiro sinal a chegar é o de uma onda próxima à superfície viajando em direção ao receptor, chamada de onda lateral. Devido à abertura do feixe a onda também alcançará a parede de fundo, sendo que as diferenças no tempo fornecem uma leitura da espessura de parede precisa e será usado para calibrações com base no tempo, geralmente em micro-segundos. Os dois outros sinais, sinal difratado da ponta da trinca superior e sinal difratado da ponta da trinca inferior, aparecem devido à falta de homogeneidade no material, ou seja, quando algum defeito está presente, revelaram MOURA et al. [5].

A Figura 1 apresenta um esquema do ensaio TOFD indicando as principais ondas presentes durante a inspeção de um componente com um defeito interno, no qual 1 se refere ao transmissor e 2 ao receptor.

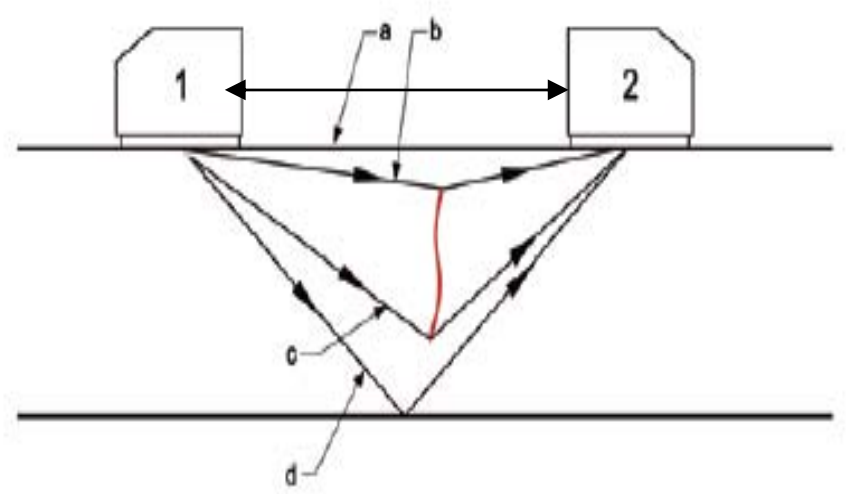

Figura 1: Desenho esquemático do ensaio TOFD: (a) Onda lateral, (b) Difração superior, (c) Difração inferior e (d) Eco de fundo. MOURA et al. [5] .

Uma onda transversal é também emitida dentro do material que se transforma em uma onda longitudinal (ou vice-versa). Estes sinais são chamados de sinais de conversão de modo. Os sinais de conversão de modo podem dar informações adicionais às indicações detectadas e algumas vezes permitir detectar anomalias bem próximas à superfície, no qual o TOFD utilizando onda longitudinal não detecta com 
precisão. BASKARAN et al. []] solucionaram o problema da superposição do sinal da onda lateral com a extremidade do defeito, quando este é próximo à superfície. Para isso ele utilizou o sinal da onda difratada transversal, também chamada de S-TOFD, e superou esta limitação da técnica. BABY et al. [9] afirmaram que ondas longitudinais são preferidas comparadas às ondas transversais por reduzir a ambigüidade nas fontes de sinais. Parâmetros como o tamanho de trinca, posição, localização e/ou forma são relativamente irrelevantes para a técnica TOFD. Os sinais difratados serão enviados para o receptor, assim, as diferenças no caminho de tempo darão uma medição mais precisa da descontinuidade.

Através do TOFD, SOUZA [10] mostrou que é possível incidir no interior do material um feixe de ultrasom inclinado em relação à superfície de inspeção a partir da escolha do ângulo de incidência e freqüência do cabeçote adequada para a inspeção proposta. MONDAL [11] citou que a taxa de crescimento médio anual (AAGR) do mercado de TOFD é de 10-20\% maior do que outras técnicas de ensaios não destrutivos. O método está ganhando popularidade devido à alta probabilidade de detecção (POD), baixa taxa de "chamada falsa", portabilidade, baixo custo e a elevada precisão intrínseca no dimensionamento de descontinuidades, especialmente na profundidade, revelou GOUJON [12]. CARNEVAL et al. [13] mostraram que o TOFD, comparada com outras técnicas não-destrutivas convencionais, é a mais apropriada para determinar a profundidade ou a altura de uma trinca. Porém o TOFD não fornece uma informação precisa sobre o tipo de defeito detectado, sendo esta informação dependente exclusivamente da experiência e conhecimento do operador, segundo MOURA et al. [14].

CARVALHO et al. [15] observaram que defeitos aflorando na superfície oposta, como a falta de penetração em um cordão de solda por exemplo, apresentam um erro no dimensionamento menor para técnicas ultra-sônicas automatizadas comparando com técnicas ultra-sônicas manuais, sendo que a probabilidade de detecção (POD) por TOFD é de 93,8\%.

Este trabalho mostra a eficiência da técnica TOFD no dimensionamento de defeitos de diferentes geometrias e profundidades, a partir da calibração de acordo com a Norma BS 7706 [16]. Esta metodologia constitui uma boa referência para avaliar o potencial e a precisão do método, servindo de base para o monitoramento automatizado de dutos, soldas e demais componentes da indústria petrolífera.

O Trabalho é parte do Projeto "Desenvolvimento de Procedimentos de Monitoração de Defeito em Dutos Rígidos para a Indústria Petrolífera”, desenvolvido em parceria com a Petrobras S/A, o qual visa o desenvolvimento de técnicas avançadas de inspeção e monitoramento de dutos rígidos.

\section{MATERIAIS E MÉTODOS}

Para a realização deste trabalho foram confeccionados 3 corpos de prova usinados por eletroerosão (CP1, CP2 e CP3) com as seguintes dimensões: $200 \mathrm{~mm}$ de comprimento, $50 \mathrm{~mm}$ de largura e $24,8 \mathrm{~mm}$ de espessura do aço SAE 1022. Os CP1 e CP2 foram utilizados para a calibração do ganho do equipamento (padrões) usando sinais difratados a partir de rasgos ou entalhes, segundo a Norma BS 7706 [16]. O CP1 apresentava um entalhe usinado em " $\mathrm{V}$ ", tendo $5 \mathrm{~mm}$ de largura, profundidade de $12,5 \mathrm{~mm}$ e o ângulo do entalhe com o eixo horizontal foi usinado em $60^{\circ}$. Já o CP2 apresentava um entalhe reto com $0,3 \mathrm{~mm}$ de largura e 8mm de profundidade. Finalmente, o CP3 teve dois defeitos simulados em diferentes profundidades, interpretados tanto pelo lado dos entalhes aflorando na superfície de varredura quanto pelo lado oposto, representando os entalhes aflorando na superfície oposta, o que indica quatro situações distintas de inspeção. Ambos os entalhes apresentavam 0,7mm de largura espaçados 70,60mm entre si, sendo que um foi usinado a uma profundidade de $12,5 \mathrm{~mm}$ e o outro, a uma profundidade de $8 \mathrm{~mm}$. O procedimento para a caracterização dos diferentes tipos de defeitos apresentados (aflorando na superfície de varredura e aflorando na superfície oposta), após calibração, teve como referência a Norma BS EN 583-6 [1]7].

Todos os corpos de prova (CP1, CP2 e CP3) foram calibrados e interpretados utilizando cada uma das quatro variações de freqüência e ângulo de incidência propostas: $5 \mathrm{MHz} / 60^{\circ}, 5 \mathrm{MHz} / 70^{\circ}, 10 \mathrm{MHz} 60^{\circ}$ e $10 \mathrm{MHz} / 70^{\circ}$. Para tais procedimentos foram utilizados diferentes conjuntos de cabeçotes e sapatas, sendo eles:

- 2 transdutores de $5 \mathrm{MHz}$ com diâmetro do cristal de 6 mm.

- 2 transdutores de $10 \mathrm{MHz}$ com diâmetro do cristal de $6 \mathrm{~mm}$.

- 2 sapatas de acrílico com onda longitudinal em $60^{\circ}$.

- 2 sapatas de acrílico com onda longitudinal em $70^{\circ}$. 
A Figura 2 apresenta, de forma resumida, a seqüência de ensaios adotada neste trabalho.

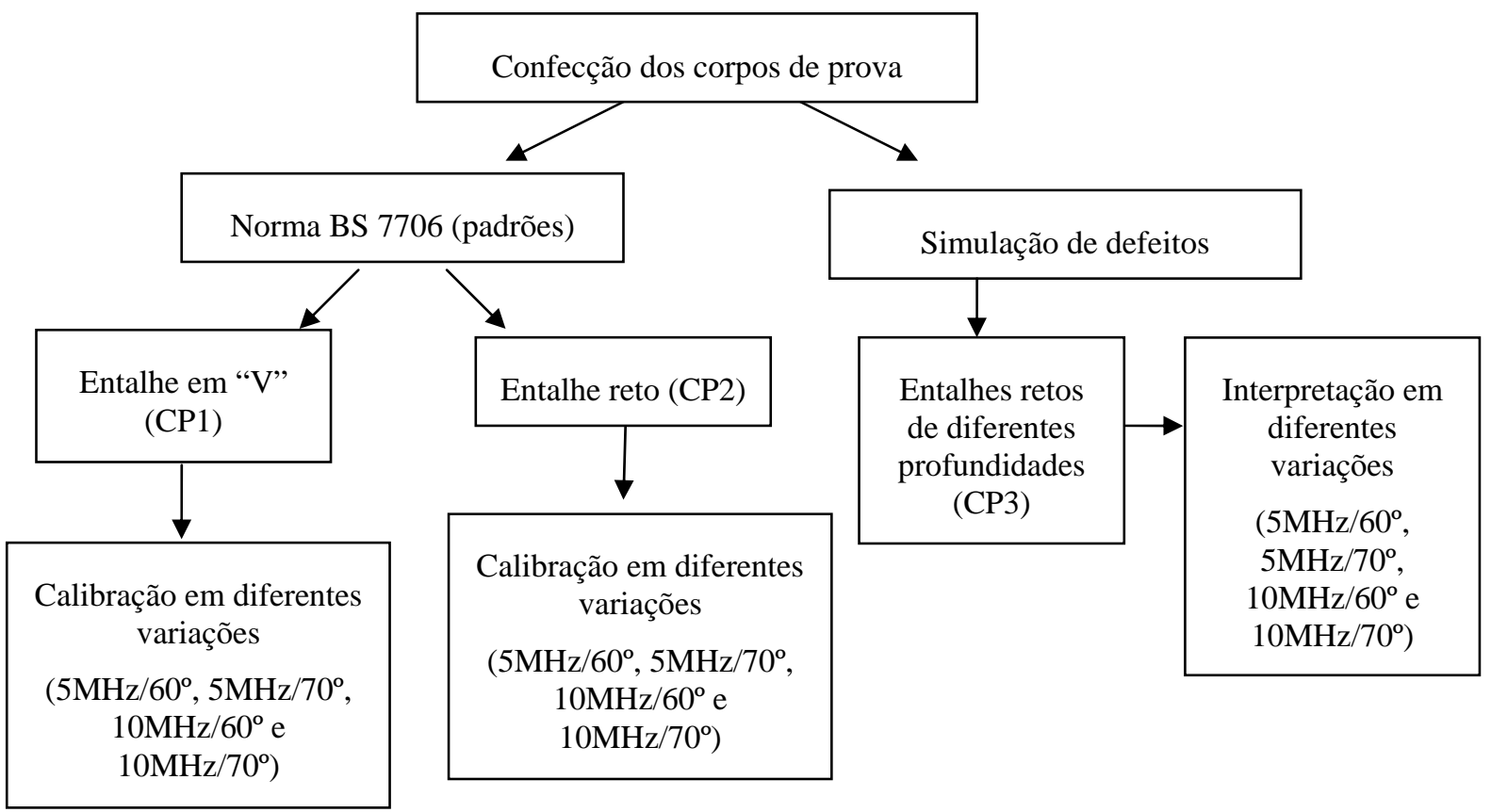

Figura 2: Fluxograma detalhado das etapas da metodologia adotada neste trabalho. CP = corpo de prova.

Para a realização dos experimentos, foi utilizado um equipamento de ultra-som de 16 canais, no qual a parte de hardware e software foi desenvolvida pela equipe da CPTi/PUC-Rio, que permite trabalhar tanto no modo pulso-eco (ultra-som convencional) quanto no modo TOFD, sendo o último, escopo deste trabalho. Desta forma, além dos transdutores e sapatas citados, foram utilizados os seguintes acessórios para a realização deste trabalho:

- Um porta-sondas (scanner) para posicionar/movimentar os cabeçotes;

- $\quad$ Corpo de prova (CP) a ser inspecionado;

- 2 cabos com conexão microdot;

- Vaselina líquida como acoplante;

- $\quad$ Placa de aquisição de dados (hardware);

- Computador pessoal e um software para aquisição de dados.

A Figura 3 apresenta o conjunto TOFD, com todos os acessórios necessários para o seu funcionamento.
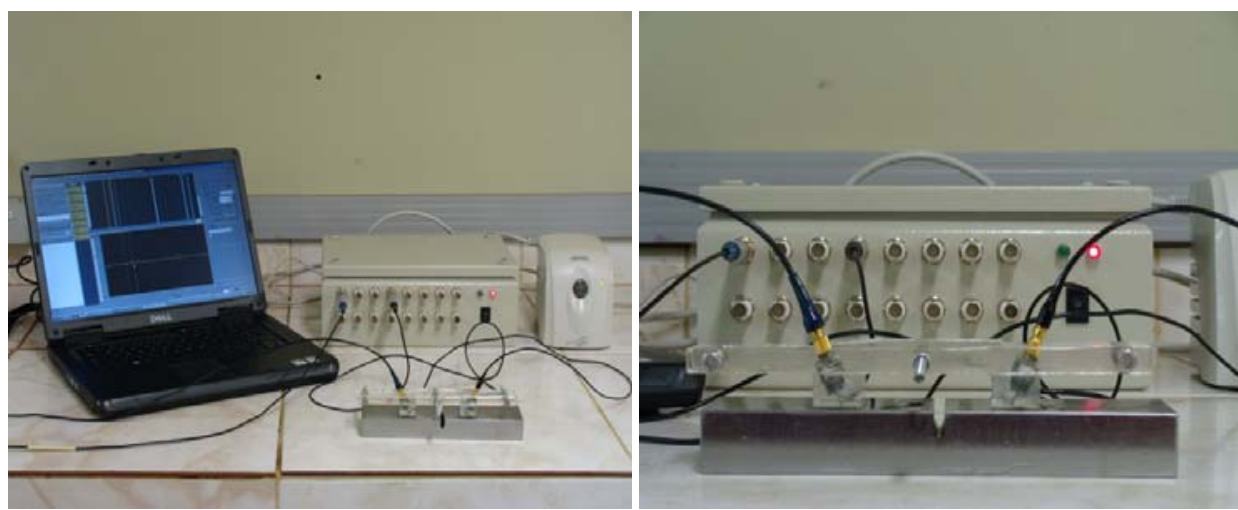

Figura 3: Equipamento de TOFD utilizado no ensaio. 


\section{RESULTADOS}

\subsection{Etapa 1: Calibração}

As Tabelas 1 e 2 apresentam os valores medidos para cada variação $(d)$ utilizados na calibração de CP1 e CP2, respectivamente.

Tabela 1: Valores de profundidade média e tempos de chegada da onda difratada para todas as variações calibradas com o CP1.

\begin{tabular}{|c|c|c|c|c|c|c|c|c|c|}
\hline \multirow[t]{2}{*}{$\begin{array}{l}\text { Profundidade } \\
\text { real do } \\
\text { entalhe(mm) }\end{array}$} & \multirow[t]{2}{*}{ Onda } & \multicolumn{2}{|c|}{$\begin{array}{c}5 \mathrm{MHz} \\
6^{\circ}\end{array}$} & \multicolumn{2}{|c|}{$\begin{array}{c}5 \mathrm{MHz} \\
70^{\circ}\end{array}$} & \multicolumn{2}{|c|}{$\begin{array}{c}10 \mathrm{MHz} \\
60^{\circ}\end{array}$} & \multicolumn{2}{|c|}{$\begin{array}{c}10 \mathrm{MHz} \\
70^{\circ}\end{array}$} \\
\hline & & $\begin{array}{l}\text { TOF } \\
(\mu s)\end{array}$ & $\begin{array}{c}d \\
(\mathrm{~mm})\end{array}$ & $\begin{array}{l}\text { TOF } \\
(\mu s)\end{array}$ & $\begin{array}{c}d \\
(\mathrm{~mm})\end{array}$ & $\begin{array}{l}\text { TOF } \\
(\mu s)\end{array}$ & $\begin{array}{c}d \\
(\mathrm{~mm})\end{array}$ & $\begin{array}{l}\text { TOF } \\
(\mu s)\end{array}$ & $\begin{array}{c}d \\
(\mathrm{~mm}) \\
\end{array}$ \\
\hline \multirow{3}{*}{$12,5 \mathrm{~mm}$} & Lateral & 14,36 & \multirow{3}{*}{13,30} & 18,18 & \multirow{3}{*}{12,15} & 14,43 & \multirow{3}{*}{13,00} & 18,09 & \multirow{3}{*}{13,11} \\
\hline & Difração & 15,43 & & 20,62 & & 15,45 & & 18,81 & \\
\hline & Fundo & 17,88 & & 18,80 & & 17,98 & & 20,61 & \\
\hline
\end{tabular}

Tabela 2: Valores de profundidade média e tempo de onda de todas as variações calibradas com o CP2.

\begin{tabular}{|c|c|c|c|c|c|c|c|c|c|}
\hline \multirow[t]{2}{*}{$\begin{array}{l}\text { Profundidade } \\
\text { real do } \\
\text { entalhe }(\mathrm{mm})\end{array}$} & \multirow[t]{2}{*}{ Onda } & \multicolumn{2}{|c|}{$\begin{array}{c}5 \mathrm{MHz} \\
60^{\circ}\end{array}$} & \multicolumn{2}{|c|}{$\begin{array}{c}5 \mathrm{MHz} \\
70^{\circ}\end{array}$} & \multicolumn{2}{|c|}{$\begin{array}{c}10 \mathrm{MHz} \\
60^{\circ}\end{array}$} & \multicolumn{2}{|c|}{$\begin{array}{c}10 \mathrm{MHz} \\
70^{\circ}\end{array}$} \\
\hline & & $\begin{array}{l}\text { TOF } \\
(\mu s)\end{array}$ & $\begin{array}{c}d \\
(\mathrm{~mm})\end{array}$ & $\begin{array}{l}\text { TOF } \\
(\mu s)\end{array}$ & $\begin{array}{c}d \\
(\mathrm{~mm})\end{array}$ & $\begin{array}{l}\text { TOF } \\
(\mu s)\end{array}$ & $\begin{array}{c}d \\
(\mathrm{~mm})\end{array}$ & $\begin{array}{l}\text { TOF } \\
(\mu s)\end{array}$ & $\begin{array}{c}d \\
(\mathrm{~mm})\end{array}$ \\
\hline \multirow[b]{3}{*}{$8 \mathrm{~mm}$} & Lateral & 14,65 & \multirow[b]{3}{*}{9,00} & 17,96 & \multirow[b]{3}{*}{9,17} & 14,43 & \multirow[b]{3}{*}{8,88} & 18,27 & \multirow[b]{3}{*}{9,25} \\
\hline & Difração & 14,93 & & 18,32 & & 14,92 & & 18,64 & \\
\hline & Fundo & 17,88 & & 20,48 & & 17,95 & & 20,51 & \\
\hline
\end{tabular}

Sabendo que as profundidades de 12,5mm e 8mm representam o 100\% (valor real), observa-se que a calibração foi eficiente para todas as variações. Para o CP1 o erro na calibração média não foi maior do que 6,5\%. Já para o CP2, não ultrapassou 16\% (Figura 4). As indicações de 1 a 3 nas Figuras 4, 5 e 6 representam as ondas principais no A-scan e B-scan: (1) onda lateral, (2) eco difratado e (3) eco de fundo. 

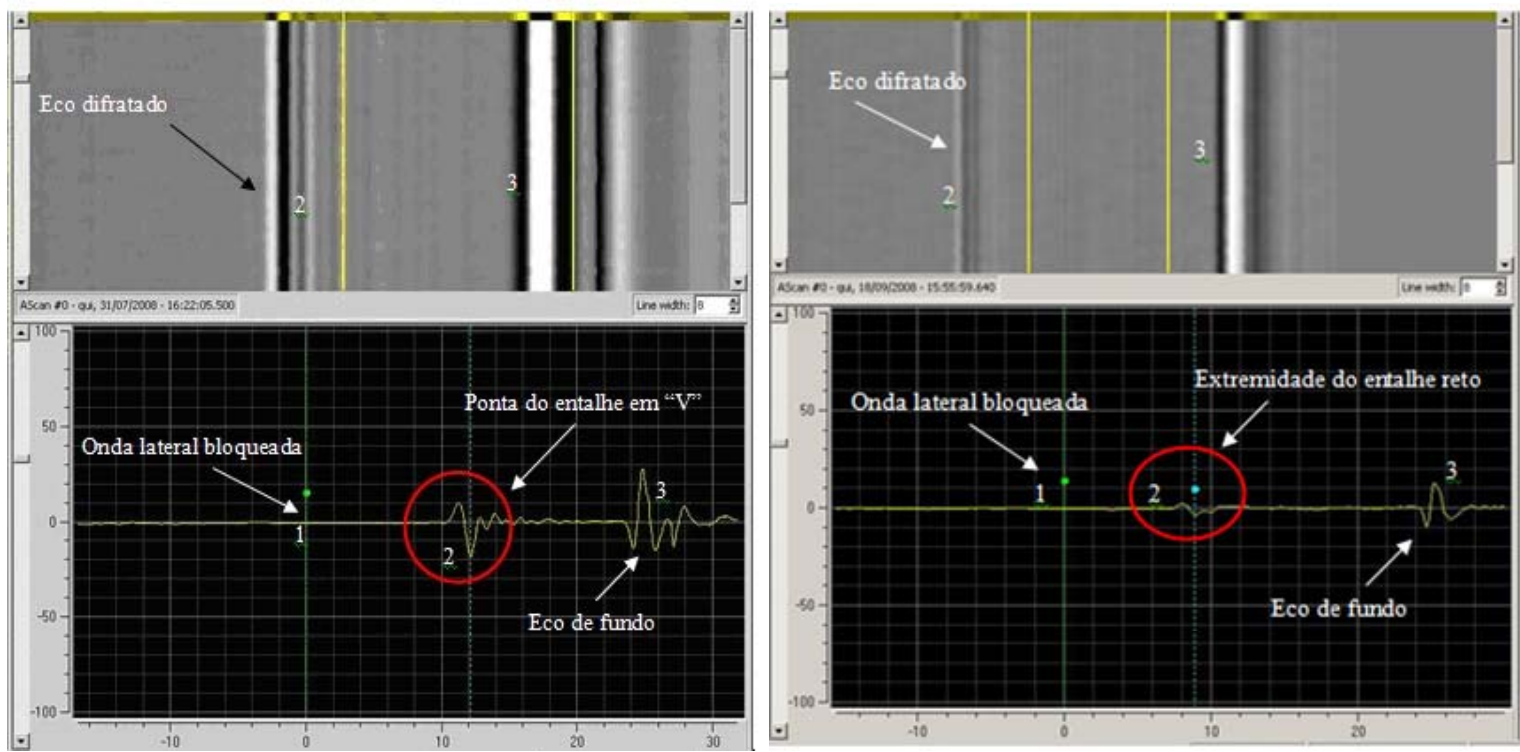

Figura 4: Ecogramas obtidos na calibração do CP1 $\left(5 \mathrm{MHz} / 70^{\circ}\right)$ e do CP2 $\left(10 \mathrm{MHz} / 60^{\circ}\right)$.

A partir da calibração do equipamento, pôde-se determinar a variação (freqüência/ângulo) mais indicada para defeitos de diferentes profundidades aflorando na superfície de varredura e aflorando na superfície oposta à varredura. Os círculos nas Figuras 5 e 6 representam bloqueio ou diminuição do eco.

\subsection{Etapa 2: Simulação de defeitos}

Os ecogramas a seguir (Figuras 5 e 6) apresentam alguns dos principais resultados obtidos para cada variação na inspeção dos entalhes simulados no CP3. As análises foram feitas com os entalhes aflorando na superfície de varredura e também aflorando na superfície oposta para todas as quatro variações propostas.

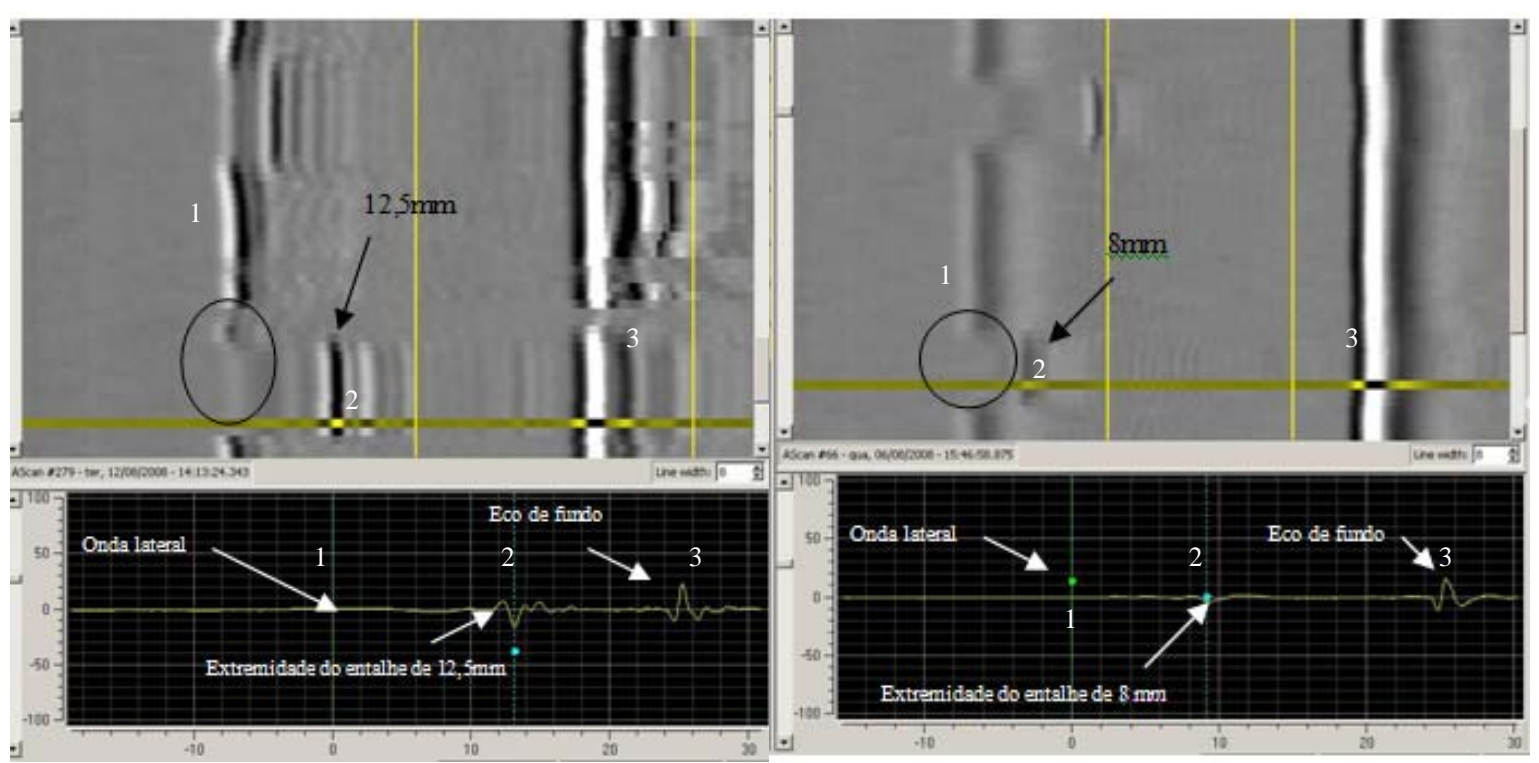

Figura 5: Ecogramas com entalhes aflorando na superfície do CP3 $\left(5 \mathrm{MHz} / 70^{\circ}\right.$ e $\left.10 \mathrm{MHz} / 60^{\circ}\right)$. 


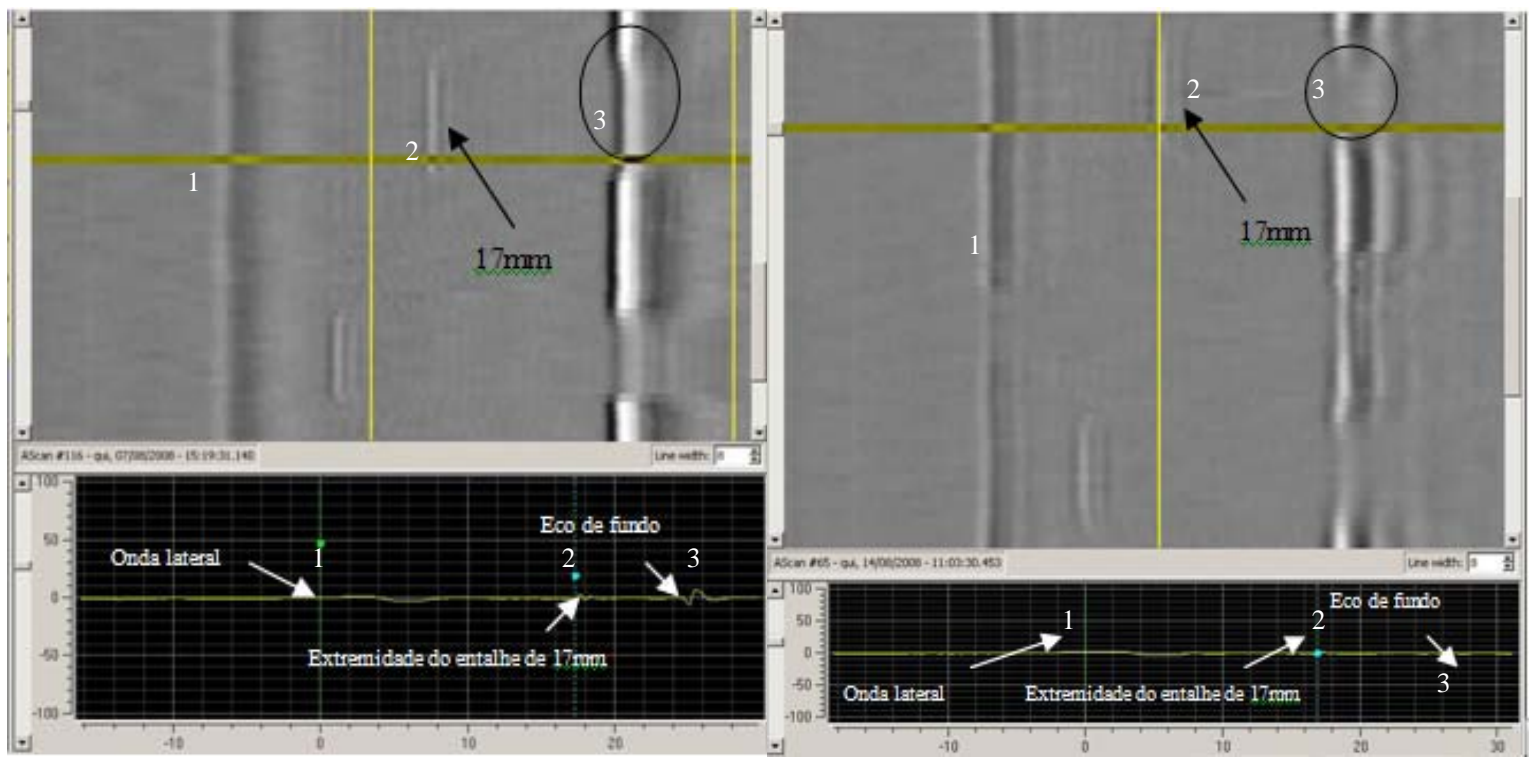

Figura 6: Ecogramas com entalhes aflorando na superfície oposta do CP3 $\left(10 \mathrm{MHz} / 60^{\circ}\right.$ e $\left.10 \mathrm{MHz} / 70^{\circ}\right)$.

Complementando, na Figura 7, os resultados de profundidades experimentais foram colocados em um gráfico de barras. Desta forma, no eixo X, a numeração de 1 a 4 se refere às diferentes profundidades de refletores analisadas, sendo os números 1 e 2 referentes aos entalhes aflorando na superfície do ensaio, sendo eles $8 \mathrm{~mm}$ e 12,5mm respectivamente. Já os números 3 e 4 se referem aos entalhes aflorando na superfície oposta à varredura, sendo eles $12,5 \mathrm{~mm}$ e $17 \mathrm{~mm}$. No eixo Y, tem-se a profundidade dos entalhes em $\mathrm{mm}$.

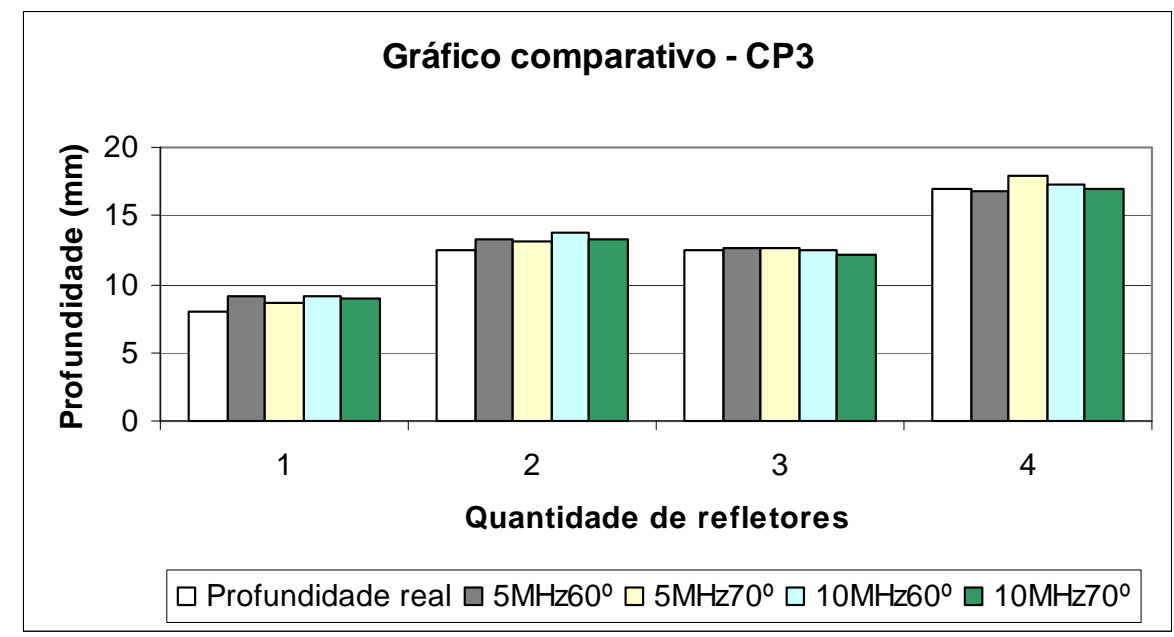

Figura 7: Gráfico comparativo mostrando as profundidades experimentais obtidas para cada variação do ensaio no CP3.

\section{DISCUSSÃO}

A calibração do equipamento se mostrou eficiente para todas as variações utilizadas, com erros experimentais não maiores do que $16 \%$. Com relação aos entalhes aflorando na superfície, tanto na profundidade de $8 \mathrm{~mm}$ quanto na profundidade de $12,5 \mathrm{~mm}$ a variação que utiliza os cabeçotes de $5 \mathrm{MHz}$ e a sapata de $70^{\circ}$ apresentou os resultados de profundidade com menor erro experimental. Já, para os cabeçotes de $5 \mathrm{MHz}$ colocados nas sapatas de $60^{\circ}$ o erro foi maior para estes entalhes aflorando na superfície de varredura. Já, aumentando a freqüência para $10 \mathrm{MHz}$ e mantendo o ângulo de sapata de $70^{\circ}$, para o entalhe mais profundo $(17 \mathrm{~mm})$ o erro no dimensionamento foi mínimo (menor que $1 \%$ ). Isto também ocorre para os cabeçotes de $10 \mathrm{MHz}$ colocados nas sapatas de $60^{\circ}$ que tiveram um melhor resultado no entalhe mais 
profundo de $17 \mathrm{~mm}$, representado pelo número 4 na Figura 7. Para um entalhe com profundidade igual à metade da espessura do corpo de prova, aflorando na superfície oposta, o dimensionamento para todas as variações apresentou um pequeno erro experimental que variou entre 0,8 e 2,2\%.

MOURA e VASCONCELOS [18], para um entalhe usinado a uma profundidade de $8 \mathrm{~mm}$ aflorando na superfície oposta à varredura, por eletroerosão, em uma chapa de $18 \mathrm{~mm}$ de espessura por 600mm de comprimento, obtiveram um erro percentual de $16,25 \%$ utilizando cabeçotes de $5 \mathrm{MHz}$ em sapatas de $60^{\circ}$, ficando próximo ao erro percentual representado na Figura 7 deste trabalho para esta variação. Neste caso, poderia ser modificado o ângulo de incidência da onda longitudinal para $70^{\circ}$ a fim de alterar a intensidade da energia ultra-sônica incidente na extremidade, diminuindo o erro experimental, como sugeriu SOUZA [10]. Já para um entalhe aflorando na superfície oposta à varredura, usinado a 13mm de profundidade, o erro percentual encontrado por MOURA e VASCONCELOS [18] ficou em 1,6\%. SOUZA [10] mostrou que esta precisão poderia ser ainda maior com a utilização de cabeçotes de maior freqüência.

SILVA et al. [6] citaram que o fato dos entalhes estarem em regiões de maior ou menor energia ultra-sônica, de acordo com o direcionamento do feixe na amostra, pode ser a causa dos resultados de profundidades serem mais profundos ou menos profundos do que o valor real, respectivamente. Neste artigo, o feixe foi direcionado para a região central do corpo de prova, isto justifica o fato do entalhe de $12,5 \mathrm{~mm}$, aflorando na superfície oposta, apresentar o resultado mais próximo do real para todas as variações, por estar em uma região de energia ultra-sônica intermediária. Este mesmo entalhe analisado, aflorando na superfície de varredura, teve profundidades experimentais maiores do que a real, por apresentar a sua extremidade inferior no caminho do feixe de maior energia ultra-sônica. Para o entalhe de $8 \mathrm{~mm}$ este fenômeno pôde ser verificado também.

\section{CONCLUSÕES}

A análise dos resultados obtidos neste artigo permite concluir que:

- $\quad$ O equipamento se mostrou aferido para o dimensionamento dos defeitos propostos.

- Para entalhes aflorando na superfície de varredura, com profundidades menores que a metade da espessura do corpo de prova, a variação que utiliza cabeçotes de $5 \mathrm{MHz}$ acoplados em sapatas com $70^{\circ}$ de ângulo é a mais indicada para o dimensionamento. Já para entalhes com profundidades maiores que a metade da espessura do corpo de prova, também aflorando na superfície oposta o dimensionamento utilizando cabeçotes de maior freqüência $(10 \mathrm{MHz})$ se mostrou mais preciso.

- Dependendo da profundidade de focalização do feixe ultra-sônico e da localização do defeito na amostra, a intensidade da energia ultra-sônica incidente em sua extremidade pode resultar em valores de profundidades experimentais mais profundos ou menos profundos. Quando a extremidade do defeito estiver na linha de foco do feixe o dimensionamento se mostra mais preciso, principalmente, aflorando na superfície oposta.

- $\quad$ O método se mostrou eficiente no dimensionamento de defeitos de diferentes profundidades sendo, portanto, indicado para sistemas automatizados de inspeção, seja no monitoramento do crescimento de trincas seja na detecção de defeitos em solda.

\section{AGRADECIMENTOS}

Os autores gostariam de agradecer ao CPTi/PUC-RJ, ao CENPES/PETROBRÁS (em especial ao Dr. Sérgio Damasceno Soares) e ao CNPq.

\section{BIBLIOGRAFIA}

[1] MARTINS, C.O.D., Desenvolvimento de metodologias de inspeção e monitoramento de risers flexíveis através de técnicas micromagnéticas de análise de tensões, Tese de D.Sc., UFRGS, Rio Grande do Sul, pp. 134, 2008.

[2] BARROS, P.M., CALDEIRA, R., “TOFD como técnica de detecção e dimensionamento de descontinuidades”, http://www.isqbrasil.com.br/tofd.htm, ISQ Brasil, 2004. 
[3] VEIGA, J., CARVAlHO, A.A., SILVA, I.C., et al., "The Use of Artificial Neural Network in the Classification of Pulse-Eco and TOFD Ultra-Sonic Signals”, Journal of the Brazilian Society of Mechanical Sciences and Engineering, v. XXVII, n. 4, October-December, 2005.

[4] SILVA, I.C., SIQUEIRA, M.H.S., OLIVEIRA, D.P.M. et al. “Automatic Inspection using the TOFD technique and neural networks”. $8^{\text {th }}$ ECNDT, Barcelona, 2002.

[5] MOURA, E.P., SIQUEIRA, M.H.S., DA SILVA, R.R. et al., "Welding defect pattern recognition in TOFD signals - Part 1: Linear classifiers”, Insight , v. 47, n. 12, December, 2005.

[6] SILVA, S.G., SILVA, I.C., REBELLO, J.M.A., “Avaliação do erro entre a técnica do tempo de percurso da onda difratada - TOFD (time of flight difraction) e as técnicas convencionais na inspeção de cordões de aços”, $6^{a}$ Conferência sobre Tecnologia de Equipamentos, Salvador-Bahia, Agosto, 2002.

[7] KENZIE, B., SPECK, J., "Structural integrity with time of flight diffraction (TOFD) ultrasonic inspection”, Inspectioneering Journal, July 2005.

[8] BASKARAN, G., BALASUBRAMANIAM, K., RAO, C.L., et al., "Shear-wave time of flight diffraction (S-TOFD) technique”, NDT \& E International, v. 39, pp. 458-467, 2006.

[9] BABY, S., BALASUBRAMANIAN, T., PARDIKAR, R.J., et al., "Time of flight diffraction (TOFD) technique for accurate sizing of surface breaking cracks”. NDT.net, National Seminar of ISNT, Chennai, 2002.

[10] SOUZA, R.R., Dimensionamento de defeitos em blocos de aço carbono através da técnica TOFD, Dissertação de M.Sc, UFRGS, pp. 108, 2009.

[11] MONDAL, S., An overview TOFD method and its mathematical model, NDT.net, v. 5 n. 4, April 2000.

[12] GOUJON, N.S., Safety implications of TOFD for in-manufacture inspections, HSE BOOKS, 2006.

[13] CARNEVAL, R.O., MOREIRA, A.B., DE SOUZA, C., et al. "Uso das Técnicas de END: Ultra-som (TOFD e Phased Array), Radiografia, Partículas Magnéticas e ACFM na Avaliação de Juntas Soldadas com Trincas de Fadiga', IV Conferencia Panamericana de END, Buenos Aires, Outubro, 2007.

[14] MOURA, E.P., DA SILVA, R.R., SIQUEIRA, M.H.S. et al, "Pattern Recognition of Weld Defects in Preprocessed TOFD Signals Using Linear Classifiers“, Journal of Nondestructive Evaluation, v. 23, n. 4, December, 2004.

[15] CARVAlHO, A.A., REBELLO, J.M.A., SOUZA, M.P.V., et al., "Reliability of non-destructive test techniques in the inspection of pipelines used in the oil industry", International Journal of Pressure Vessels and Piping, v. 85, n. 81, pp. 745-751, 2008.

[16] BS EN 7706, "Guide to Calibration and setting-up of the ultrasonic time of flight diffraction (TOFD) technique for the detection, location and sizing of flaws”, British Standard, December, 1993.

[17] BS EN 583-6, "Non-destructive testing. Ultrasonic examination. Time of flight diffraction technique as a method for detection and sizing of discontinuities”, European TOFD Standard, 2008.

[18] MOURA, E.P., VASCONCELOS, A.A., "Development of an automatic inspection equipment based on the TOFD technique”, 18 ${ }^{\text {th }}$ International Congress of Mechanical Engineering, November, 2006. 